\title{
Structural-Group Composition of Heavy Oil Conversion Products Using FTIR Spectroscopy
}

\author{
Ilmira M. Abdrafikova*1, Galina P. Kayukova ${ }^{1,2}$
}

${ }^{*}$ Kazan Federal University, ${ }^{2}$ A.E. Arbuzov Institute of Organic and Physical Chemistry, Kazan Scientific Centre, Russian Academy of Sciences

*Email: nofretary@mail.ru, Contact+79179312884.

Received: 15th December 2017, Accepted: 20th December 2017, Published: 31st December 2017

\begin{abstract}
The decrease of oil production with its simultaneous price increase and a growing demand for petroleum products leads to the importance increase of heavy hydrocarbon raw materials. The processing of heavy petroleum raw materials in water vapor using oxide type catalysts containing the metals of variable valence is a promising trend, but there are some problems for the study of liquid and solid conversion products of such raw materials that differ from traditional fractions of oil refining. There is the need to choose an informative research method that allows to analyze the structure and the composition of the products obtained quickly and with great accuracy. One of such methods is Fourier infrared spectroscopy method, widely used to study the structural-group composition of oil and petroleum products, which allows to determine more precisely the presence of certain functional groups in the composition of the products under study as compared to the chemical methods. Using Fourier infrared spectroscopy method, they studied the products of hydrothermal-catalytic conversion of heavy oil in a water vapor medium and in the presence of a natural hematite catalyst at the temperatures of 210,250 and $300{ }^{\circ} \mathrm{C}$. The effect of temperature and water content in the reaction mixture on the yield and the composition of experiment products is shown. Under the experimental conditions, a new formation of hydrocarbons takes place due to the destruction of high-molecular hydrocarbons, resins and asphaltenes. It has been established that the increase of temperature and the decrease of water content lead to the increase of test product aromaticity and oxidation degree with the development of insoluble asphaltene and coke product fraction. The method of Fourier infrared spectroscopy makes it possible to fix changes in the composition of products with a great accuracy and can serve as the control of heavy hydrocarbon raw material processing.
\end{abstract}

Keywords: Petroleum, Composition, Asphaltenes, Conversion, Catalytic Transformations, Coke, FTIR Spectroscopy

\section{Introduction}

The decrease of oil production with its simultaneous price increase and the growing demand for petroleum products leads to the increase of heavy hydrocarbon raw material importance. The processing of heavy petroleum raw materials in water vapor using oxide type catalysts containing the metals of variable valence is a promising trend [1-6], but there are some problems concerning the study of liquid and solid products of such raw material conversion, which differ from traditional fractions of oil refining [1-14]. There is a need to select an informative research method that allows you to analyze the structure and the composition of obtained products quickly and accurately. One of such methods is Fourier infrared spectroscopy method, widely used to study the structural-group composition of oil and petroleum products, which allows us to identify functional groups more accurately as compared to chemical methods [1524].

The aim of the work was to study the chemical transformations of high-molecular components of heavy oil during its thermal catalytic conversion using Fourier infrared spectroscopy spectroscopy method.

\section{Methods}

The objects of the study were heavy oil from the Ashalchinsky deposit in Permian deposits of Tatarstan and the products of its conversion in water vapor medium with natural hematite catalyst. Heavy oil conversion experiments were carried out for 2 hours in 1liter autoclave at 210,250 and $300{ }^{\circ} \mathrm{C}$ with the water-oil content ratio of 1:1, 1:5, 1:10 in the reaction system within indicated temperatures, respectively. The catalyst was represented by powdered hematite containing $41 \%$ of iron and $58 \%$ of silicon with the impurities of some other minerals dispersed in raw materials. The initial pressure was $2 \mathrm{MPa}$, which increased to $17 \mathrm{MPa}$ in the course of the experiment.

The liquid test products were subjected to atmospheric fractional distillation up to $250{ }^{\circ} \mathrm{C}$. From the residues above $250{ }^{\circ} \mathrm{C}$, asphaltenes were precipitated in a 40-fold amount of petroleum ether by a standard procedure. Maltens were divided into the following components by liquid-adsorption chromatography: oils, benzene resins, alcoholbenzene resins (oils were eluted by petroleum ether with the addition of $15 \%$ of $\mathrm{CCl} 4$, benzene resins were eluted with benzene, alcohol-benzene resins were obtained by displacement chromatography with isopropyl alcohol and benzene mixture taken in the ratio of 1:1). At the temperatures of 250 and 300 
${ }^{\circ} \mathrm{C}$, the development of coke-like products was observed. The initial objects and the products of the experiments were studied by the method of Fourier infrared spectroscopy on the infrared spectrometer Vector 22 (Bruker) in the range of 2000-400 cm-1 with the resolution of $4 \mathrm{~cm}-1$ in the optical spectroscopy laboratory IOFH named after A.E. Arbuzov at KazSC of RAS. In order to register the infrared spectra of asphaltenes in solid phase, they prepared the pills by the compaction of studied products powder with $\mathrm{KBr}$. The spectra were processed using the OPUS software package (Bruker).

In order to study the structural-group composition of the products under study, spectral coefficients were used, determined as the ratios of the optical density values at the maxima of the corresponding absorption bands: $\mathrm{C}_{1}=\mathrm{D}_{1600} / \mathrm{D}_{720}$ (aromaticity); $\mathrm{C}_{2}$ $=\mathrm{D}_{1710} / \mathrm{D}_{1465}$ (oxidation); $\mathrm{C}_{3}=\mathrm{D}_{1380} / \mathrm{D}_{1465}$ (branching); $\mathrm{C}_{4}=\left(\mathrm{D}_{720}+\mathrm{D}_{1380}\right) / \mathrm{D}_{1600}$ (paraffin content); $C_{5}=D_{1030} / D_{1465}$ (sulphuration) (Figure 1).

The liquid phase from the coke of the experiment 3 was extracted with the mixture of organic solvents (benzene-chloroform-isopropyl alcohol, taken in the ratio of $1: 1: 1)$.

Using a scanning electron microscope (SEM) Hitachi TM 1000, the microphotographs of experiment solid products were taken.

\section{Results}

The carried out researches showed that under the influence of hydrothermal-catalytic factors significant changes were observed in the component composition of oil (Table 1). In all experiments, irrespective of temperature and the amount of water introduced into the reaction system of water, the yield of hydrocarbons increases due to the decrease of benzene and alcohol-benzene resin content. At the temperature of $210^{\circ} \mathrm{C}$ and the ratio of water to oil $1: 1$ (experiment 1), the content of benzene and alcohol-benzene resins is almost three times lower. The content of asphaltenes decreases not so sharply. With the temperature increase up to $250{ }^{\circ} \mathrm{C}$ and the decrease of water-oil content to the ratio of 1:5 in the reaction system (test 2), the content of asphaltenes increases from 5.8 to $7.46 \%$. Their composition has 2 fractions: "usual" asphaltenes, soluble in aromatic solvents (Fr. A) and insoluble asphaltenes (Fr.B). The development of coke-like products begins $(2.88 \%)$, which precipitate from the liquid phase on the reactor walls.

Under the test conditions at the highest temperature of $300{ }^{\circ} \mathrm{C}$ (experiment 3), an intensive formation of coke $(24.88 \%)$ occurs with a significant decrease of asphaltenes and resins content, the development of light fractions occurs, but their yield decreases as compared to the experiment 1 and 2 . The asphaltenes of this experiment products also consist of two fractions: soluble and insoluble in toluene.

Table 1. General Characteristics and Component Composition of Ashalchinsky Oil and the Products of its Thermal-Catalytic Transformations

\begin{tabular}{|c|c|c|c|c|c|c|c|c|c|}
\hline \multirow{3}{*}{$\begin{array}{l}\text { Item } \\
\text { № }\end{array}$} & \multirow{3}{*}{ Object } & \multicolumn{8}{|c|}{ Component Composition, wt. \% } \\
\hline & & \multirow[b]{2}{*}{$\mathrm{HC}$} & \multirow[b]{2}{*}{$\mathrm{BR}$} & \multirow[b]{2}{*}{ ABR } & \multirow[b]{2}{*}{$\sum_{\text {resins }}$ of } & \multicolumn{3}{|c|}{ Asphaltenes } & \multirow[b]{2}{*}{ Coke } \\
\hline & & & & & & Fr. A & Fr. Б & $\begin{array}{l}\sum_{\text {asph. }} \\
\end{array}$ & \\
\hline \multicolumn{10}{|c|}{ Ashalchinsky deposit oil (original) } \\
\hline 1 & Residue above $250^{\circ} \mathrm{C}$ & 54,57 & 25,11 & 14,15 & 39,26 & 6,17 & - & 6,17 & - \\
\hline 2 & Oil & 57,30 & 23,60 & 13,30 & 36,90 & 5,80 & - & 5,80 & - \\
\hline \multicolumn{10}{|c|}{ Test product $1\left(T=210^{\circ} \mathrm{C}, P=17 \mathrm{MPa}\right.$, water $1: 1$, catalyzer $\left.2 \%\right)$} \\
\hline 3 & Residue above $250^{\circ} \mathrm{C}$ & 38,68 & 30,8 & 18,26 & 49,06 & 12,26 & - & 12,26 & - \\
\hline 4 & Oil & 77,14 & 11,48 & 6,81 & 18,28 & 4,57 & - & 4,57 & - \\
\hline \multicolumn{10}{|c|}{ Test product $2\left(T=250^{\circ} \mathrm{C}, \mathrm{P}=17 \mathrm{MPa}\right.$, water $1: 5$, catalyzer $\left.2 \%\right)$} \\
\hline 5 & Residue above $250^{\circ} \mathrm{C}$ & 35,83 & 28,37 & 10,09 & 38,46 & 3,88 & 21,83 & 25,71 & - \\
\hline 6 & Oil & 78,50 & 8,23 & 2,93 & 11,16 & 1,13 & 6,33 & 7,46 & 2,88 \\
\hline \multicolumn{10}{|c|}{ Test product $3\left(T=300^{\circ} \mathrm{C}, \mathrm{P}=17 \mathrm{MPa}\right.$, water $1: 10$, catalyzer $\left.2 \%\right)$} \\
\hline 7 & Residue above $250^{\circ} \mathrm{C}$ & 44,66 & 42,8 & 5,58 & 48,38 & 6,87 & 0,09 & 6,96 & - \\
\hline 8 & Oil & 59,61 & 12,00 & 1,56 & 13,56 & 1,92 & 0,03 & 1,95 & 24,88 \\
\hline
\end{tabular}

HC - Hydrocarbon (oils); BR - Benzene Resins; ABR - Alcohol-Benzene Resins; asph. - Asphaltenes; Fr. A - The fraction of asphaltene soluble in toluene; Fr. B - the fraction of asphaltenes insoluble in toluene 
According to IR spectral analysis data the content increase of aromatic structures and the content of paraffinic structure decrease takes place in original oil, as evidenced by the increase of the aromaticity index values $\left(\mathrm{C}_{1}=\mathrm{D}_{1600} / \mathrm{D}_{720}\right)$ with paraffin content decrease $\left(C_{4}=\left(D_{720}+D_{1380}\right) / D_{1600}\right.$ (Table 2). The most noticeable changes are observed at the temperatures of 250 and $300{ }^{\circ} \mathrm{C}$, which indicates the separation of long alkyl substituents in the products under study and the course of their destruction and dehydrogenation processes. Oxidation $\left(\mathrm{C}_{2}=\mathrm{D}_{1710} /\right.$ $\left.\mathrm{D}_{1465}\right)$ and sulphidity $\left(\mathrm{C}_{5}=\mathrm{D}_{1030} / \mathrm{D}_{1465}\right)$ value increase is observed in a row from the initial oil to the products of its conversion in experiments 1,2 and 3 , which indicates that there are the processes of thermal-oxidative cracking take place at temperatures of $250,300{ }^{\circ} \mathrm{C}$.

Table 2. The Results of IR-Spectral Analysis of Original Oil, its Components and Test Products

\begin{tabular}{|c|c|c|c|c|c|}
\hline \multirow{2}{*}{$\begin{array}{l}\text { Object of the } \\
\text { Study }\end{array}$} & \multicolumn{5}{|c|}{ Spectral Indicators* } \\
\hline & $C_{1}$ & $C_{2}$ & $C_{3}$ & $C_{4}$ & $C_{5}$ \\
\hline \multicolumn{6}{|c|}{ Ashalchinsky deposit oil (original) } \\
\hline Oil & 0,90 & 0 & 0,45 & 6,53 & 0,02 \\
\hline Oils & 0,44 & 0,01 & 0,49 & 14,29 & 0,02 \\
\hline $\mathrm{BR} * *$ & 1,47 & 0,09 & 0,47 & 4,43 & 0,13 \\
\hline ABR & 2,51 & 0,26 & 0,49 & 2,23 & 0,20 \\
\hline Asphaltenes & 3,40 & 0,01 & 0,57 & 1,62 & 0,11 \\
\hline \multicolumn{6}{|c|}{ Test product $1\left(T=210^{\circ} \mathrm{C}, P=17 \mathrm{MPa}\right.$, water $1: 1$, catalyzer $\left.2 \%\right)$} \\
\hline Test product & 1,04 & 0,03 & 0,50 & 6,24 & 0,03 \\
\hline Oils & 0,36 & 0,01 & 0,46 & 16,12 & 0,02 \\
\hline BR & 1,10 & 0,06 & 0,48 & 4,87 & 0,09 \\
\hline ABR & 2,85 & 0,37 & 0,50 & 2,17 & 0,19 \\
\hline Asphaltenes & 6,00 & 0,04 & 0,53 & 1,57 & 0,14 \\
\hline \multicolumn{6}{|c|}{ Test product $2\left(T 250^{\circ} \mathrm{C}, P=17 \mathrm{MPa}\right.$, water $1: 5$, catalyzer $\left.2 \%\right)$} \\
\hline Test product & 1,25 & 0,02 & 0,44 & 3,52 & 0,07 \\
\hline Oils & 1,36 & 0 & 0,48 & 3,67 & 0,08 \\
\hline BR & 1,98 & 0,02 & 0,47 & 1,89 & 0,18 \\
\hline ABR & 25,76 & 1,10 & 0,79 & 1,03 & 0,23 \\
\hline Asphaltenes fr. A & 7,99 & 0,60 & 0,58 & 0,75 & 0,24 \\
\hline Asphaltenes fr. Б & 3,23 & 0,00 & 0,72 & 0,91 & 0,25 \\
\hline Coke & 3,13 & 0,08 & 0,77 & 1,07 & 0,23 \\
\hline \multicolumn{6}{|c|}{ Test product $3\left(T 250^{\circ} \mathrm{C}, \mathrm{P}=17 \mathrm{MPa}\right.$, water $1: 10$, catalyzer $\left.2 \%\right)$} \\
\hline Test product & 2,64 & 0,09 & 0,42 & 1,39 & 0,17 \\
\hline Oils & 3,06 & 0,01 & 0,51 & 1,69 & 0,15 \\
\hline $\mathrm{BR}$ & 1,56 & 0,005 & 0,41 & 1,56 & 0,21 \\
\hline ABR & 5,71 & 1,02 & 0,41 & 0,70 & 0,26 \\
\hline Asphaltenes fr. A & 3,13 & 0,56 & 0,56 & 0,83 & 0,28 \\
\hline Asphaltenes fr. Б & 7,55 & 0,38 & 0,99 & 0,61 & 0,44 \\
\hline Coke & 0,97 & 0,30 & 1,37 & 1,53 & 0,50 \\
\hline
\end{tabular}


$* C_{1}=D_{1600} / D_{720}$ (aromaticity); $C_{2}=D_{1710} / D_{1465}$ (oxidation); $C_{3}=D_{1380} / D_{1465}$ (branching); $C_{4}=\left(D_{720}+D_{1380}\right)$ $/ D_{1600}$ (paraffin content); $C_{5}=D_{1030} / D_{1465}$ (sulphuration); $* * B R$ - benzene resins; $A B R$ - alcohol-benzene resins; $\mathrm{Fr}$. A - the fraction of asphaltenes soluble in toluene; Fr. B - the fraction of asphaltenes insoluble in toluene

The analysis of the infrared spectra of individual components (oils, benzene resins, alcohol-benzene resins from the residue above $250{ }^{\circ} \mathrm{C}$, asphaltenes and coke) of the products under study revealed common features and differences in their structure (Fig. 1-5).

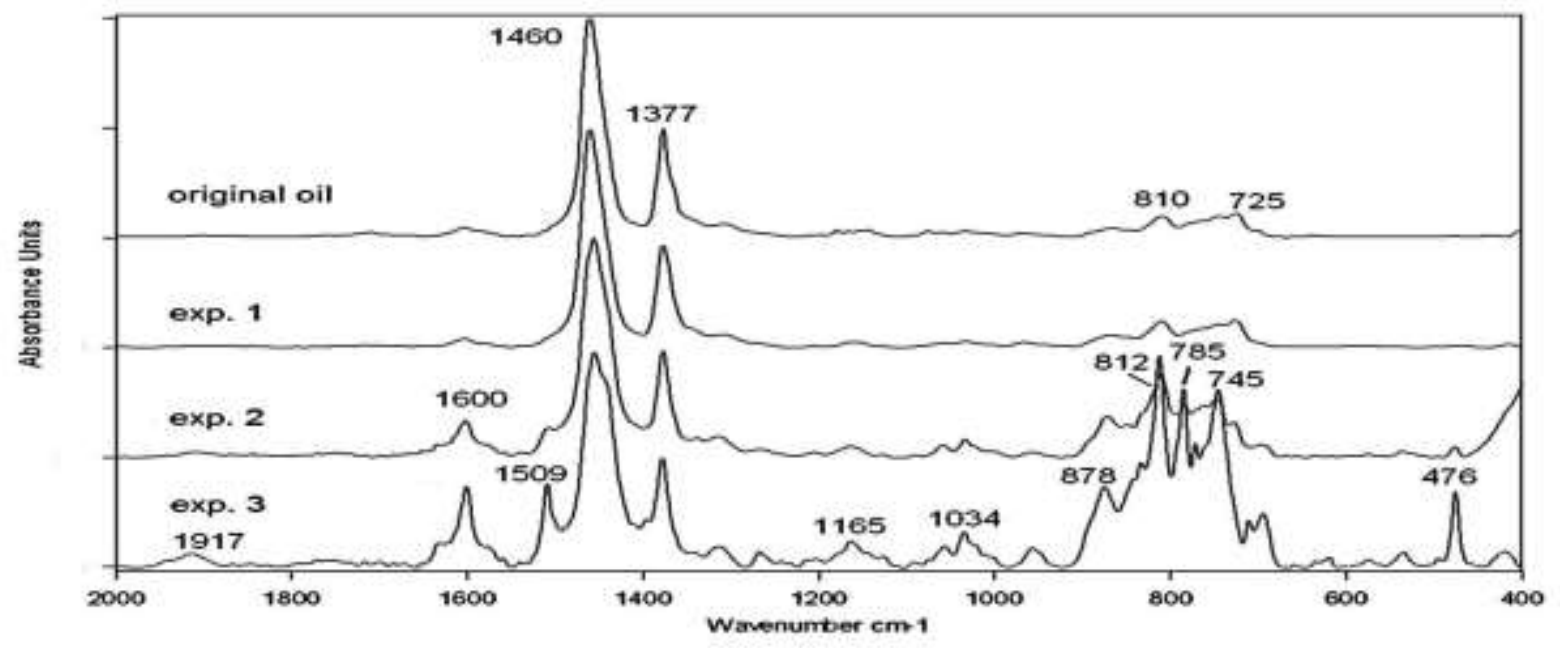

Fig. 1. Infrared Spectra of Oils from Original Oil and its Conversion Products

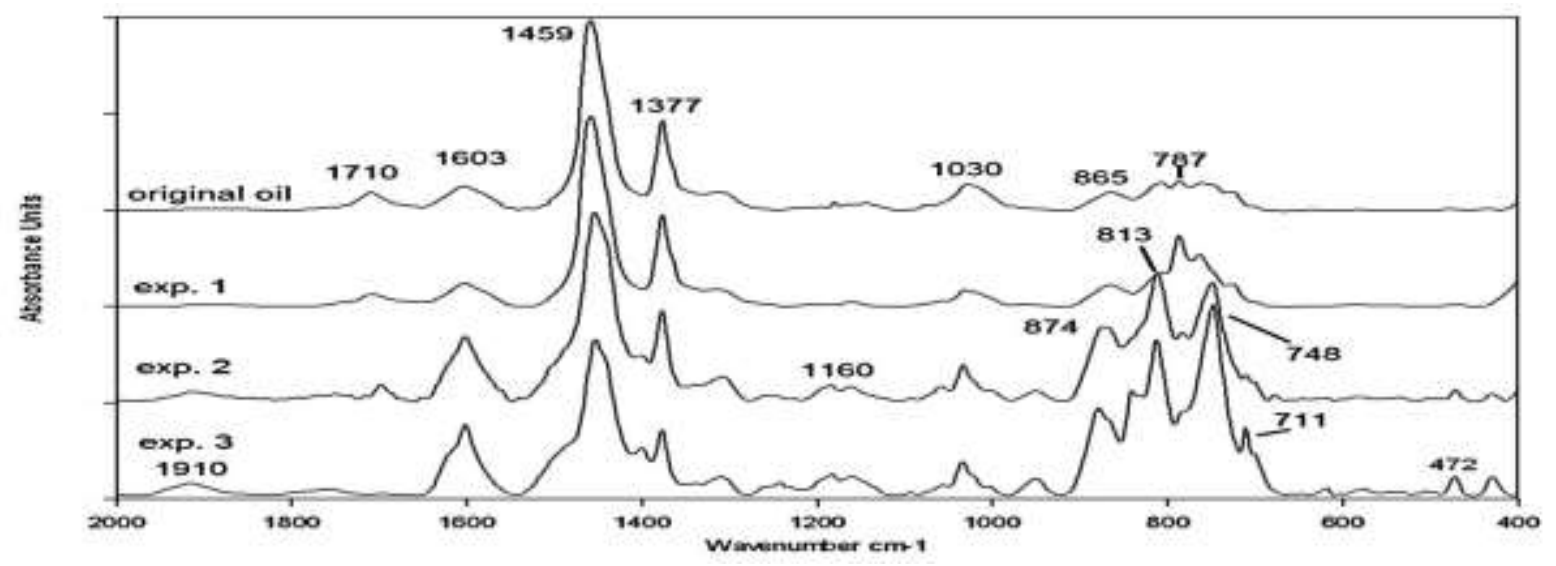

Fig. 2. Infrared Spectra of Benzene Resins from Original Oil and its Conversion Products

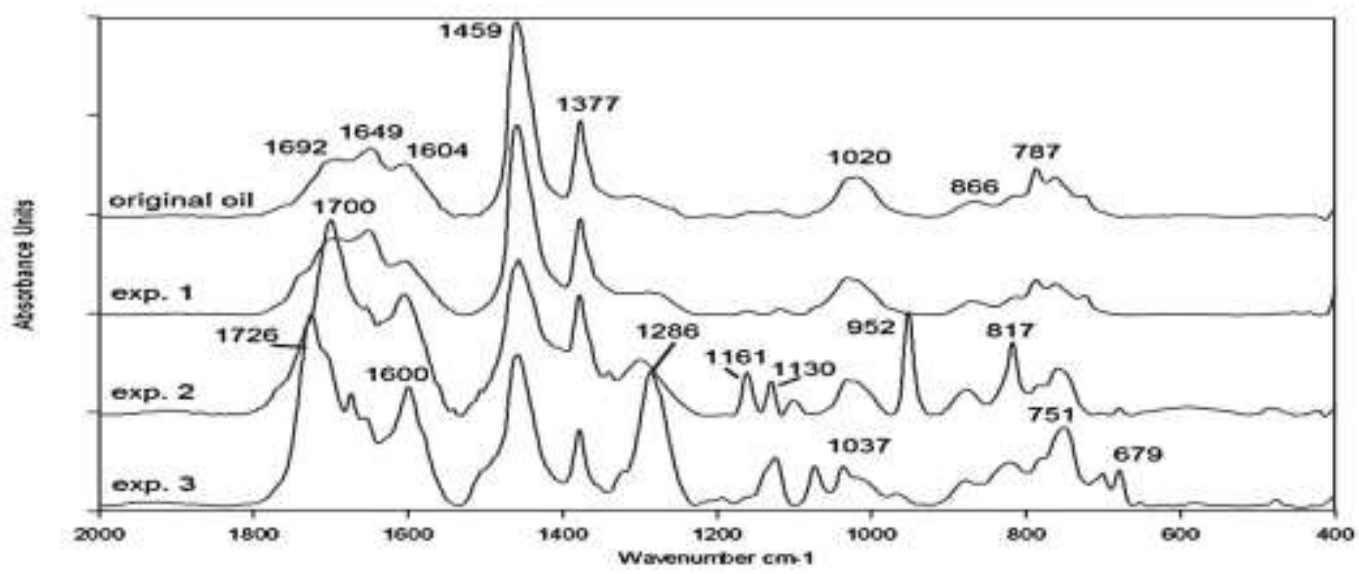


Fig. 3. Infrared Spectra of Alcohol-Benzene Resins from Original Oil and its Conversion Products

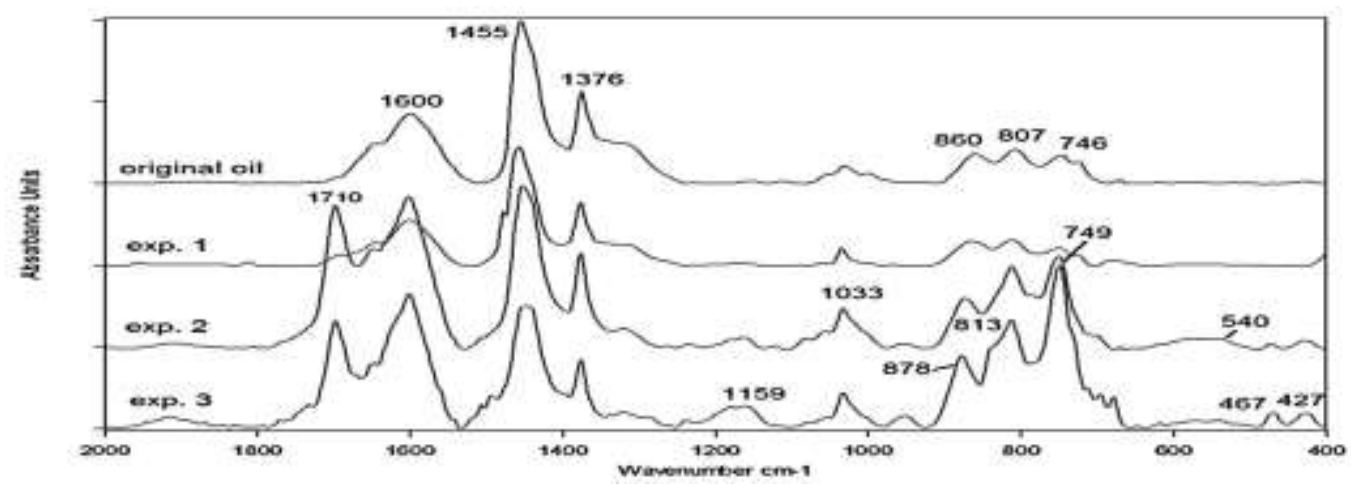

Fig. 4. Infrared Spectra of Asphaltenes (Fr. A) from Original Oil and the Products of its Conversion a)

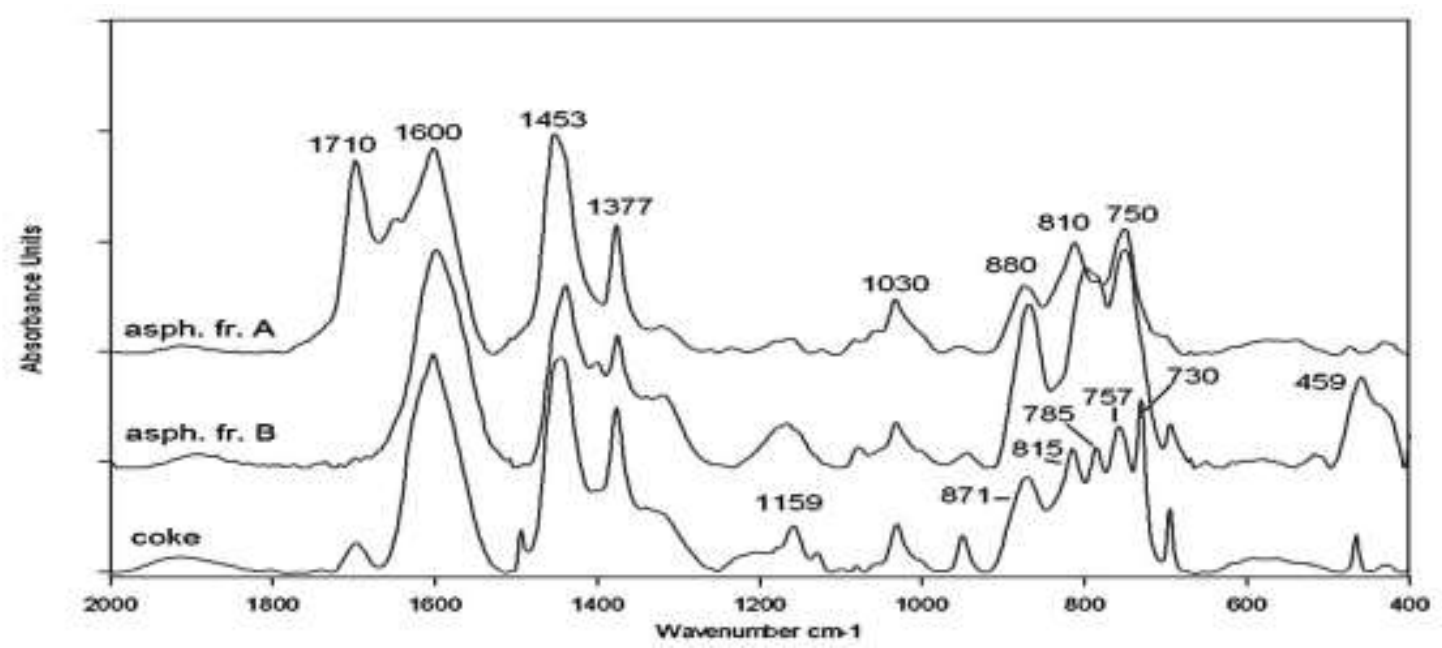

b)

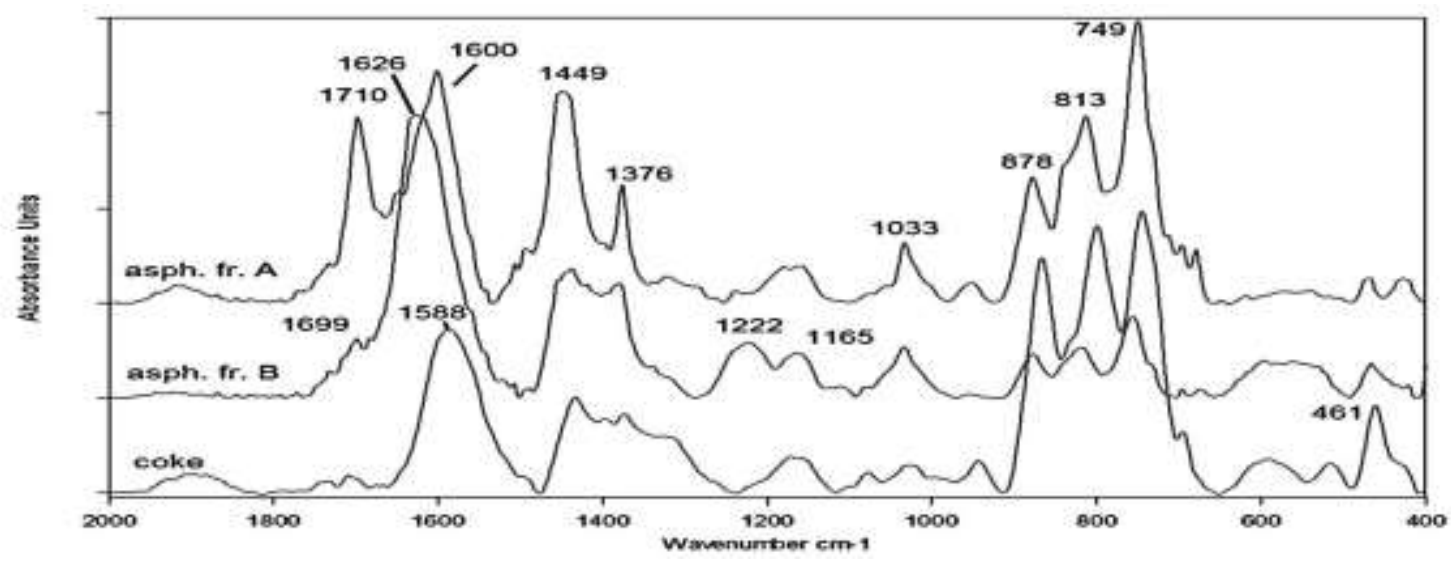

Fig. 5. Infrared Spectra of Asphaltenes (fr. A and B) and Coke-Like Products of Heavy Oil conversion: a) - experiment 2, b) - experiment 3

Fig. 6 demonstrates the diagram of component distribution in the liquid phase extracted from the coke surface (experiment 3), as well as in the composition of this experiment liquid products. 


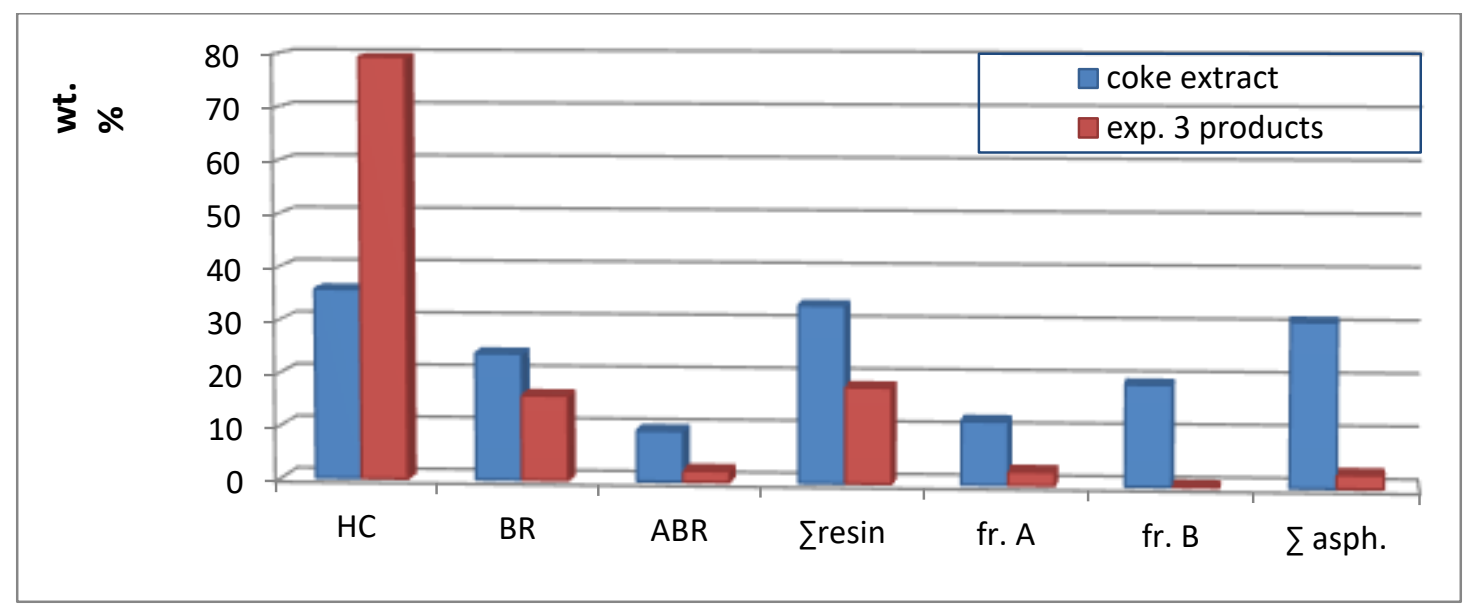

Fig. 6. Component Distribution Diagram in the Extract from the Coke of the Experiment 3 and the Products of this Experiment. HC - Hydrocarbons; BR - Benzene Resins; ABR - Alcohol-Benzene Resins; $\sum$ resin -Resins

Total; fr. A - Fraction of Asphaltenes Soluble in Toluene; fr. B - Fraction of Asphaltenes Insoluble in Toluene; $\sum$ asph. - Asphaltenes Total

Fig. 7 shows the photomicrographs of the coke surface before and after the extraction of the liquid phase from it.

a)

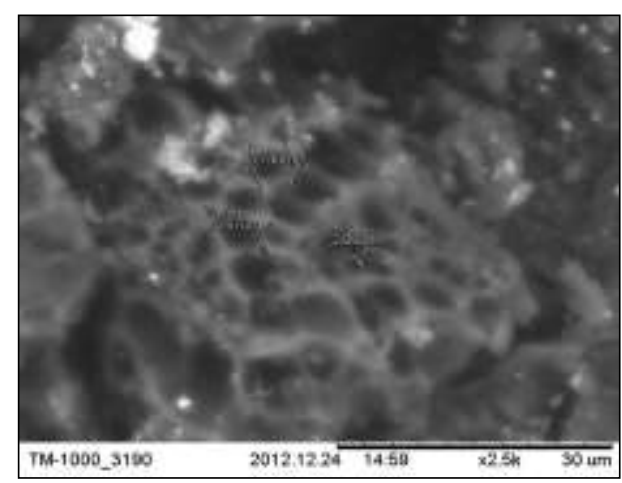

б)

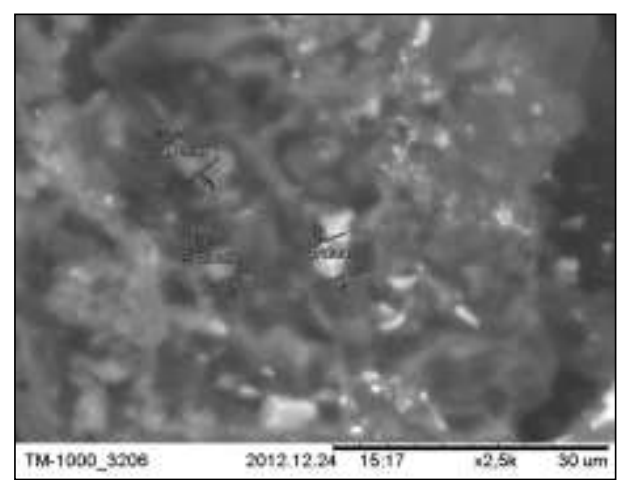

Fig. 7. Morphology of the Coke-Product Surface after the Experiment 3 by Scanning Electron Microscopy before (a) and after (b) the Extraction

Infrared method in the wavelength range of 4000$400 \mathrm{~cm}-1$ was used to study the catalyst before and after the experiment 1 , in the products of which have less noticeable changes (Fig. 8). For comparison, this figure shows the coke spectrum of the experiment 2 .

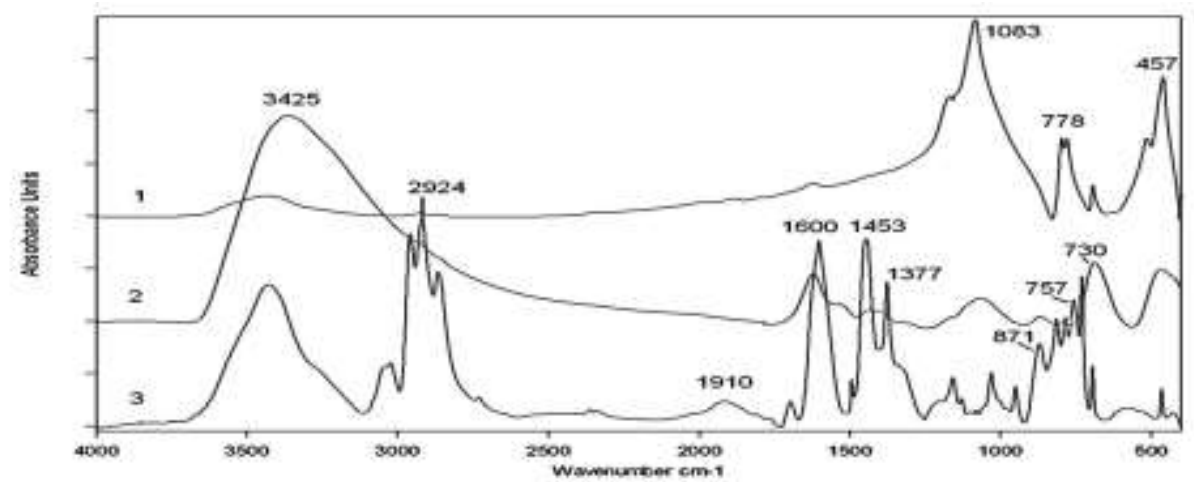

Figure 8. Infrared Spectra of the Hematite Catalyst: 1) - Initial Hematite, 2) - After the Experiment 1 and 3) the Coke from the Products of the Experiment 2. 


\section{Discussion}

Oils. The infrared spectra of Ashalchinsky oil and the products of its conversion (Figure 1) has specific intense absorption bands of aliphatic structures at $1380 \mathrm{~cm}^{-1}$ (methyl $\mathrm{CH} 3$ groups) and $1465 \mathrm{~cm}^{-1}$ (methylene $\mathrm{CH} 2$ groups) as well as a band with its maximum at $725 \mathrm{~cm}^{-1}$, corresponding to long methylene chains $(\mathrm{CH} 2>4)[12,17,26]$.

The infrared spectrum of the oils from the products of the experiment $1\left(210^{\circ} \mathrm{C}\right)$ differs little from the range of oils of the original oil (Figure 1), however, their aromaticity (Table 2, index $\mathrm{C} 1$ ) decreases slightly as the degree of aliphaticity increases (indicator C4). The increase in the yield of hydrocarbons under the conditions of this experiment (Table 1) indicates the processes of long paraffin chain destruction with the formation of low-molecular fragments. More significant changes, but towards the growth of aromaticity, are observed in the infrared spectra of oils from the products of the experiment 2 and 3 (Table 2), as evidenced by a significant increase of the absorption band intensity at $1600 \mathrm{~cm}^{-1}$, which was practically absent in the initial oil (Figure 1). The spectra of the oils in the products of the experiment 2 and 3 demonstrate this absorption band intensity increase, and the intensity increase of the absorption bands in the region of $900-730 \mathrm{~cm}^{-1}, 745$ $\mathrm{cm}^{-1}$, associated with the vibration of 4 hydrogen atoms adjacent to the aromatic ring, and 785,812 $\mathrm{cm}^{-1}$, corresponding to the out-of-plane deformation vibrations of the $\mathrm{C}-\mathrm{H}$ bond of condensed aromatic rings [25, 28]. In the infrared spectra of experiment 3 products, the abovementioned peaks become narrower and more intense, which, according to the data of [28], may indicate the development of polyaromatic structures. Besides, a narrow band of medium intensity at $1509 \mathrm{~cm}^{-1}$ appears in the spectrum of experiment 3 product oils (Figure 1), which is characteristic of nitrogen-containing compounds of a heterocyclic structure [21], which may indicate the appearance of heterocyclic fragments in the composition of these oils that are the products of resin and asphaltene decomposition.

It should be noted that the spectra of product oils from the experiment 2 and 3, obtained at the temperatures of 250 and $300{ }^{\circ} \mathrm{C}$, the absorption bands appear in the region of $1200-1100 \mathrm{~cm}-1$, corresponding to the vibrations of oxygencontaining groups of C-O-C, C-OH (alcohols, ethers), which become more intense as the temperature of the experiment increases. This confirms the course of oxidative cracking processes, which is also indicated by a broad absorption band at $1910 \mathrm{~cm}-1$, which can be attributed to oxygen compounds, such as carbon monoxide [22] or formaldehyde [23].
Benzene resins. In contrast to oils the spectra of the benzene resins of the initial oil and the conversion products (Fig. 2) have more intense absorption bands of $1600 \mathrm{~cm}-1$, corresponding to the aromatic structures $(\mathrm{C}=\mathrm{C}$ bond in a benzene ring) and an aromatic triplet in the range of $900-730 \mathrm{~cm}-1$. The broad bands of low intensity with the maxima at $1710 \mathrm{~cm}-1$ (the valent vibrations of the $\mathrm{C}=\mathrm{O}$ bond in the carbonyl groups of acids) and at $1030 \mathrm{~cm}-1$ (the valent vibrations of $\mathrm{S}=\mathrm{O}$ bond in the sulfoxide groups) also appear.

The changes in the structure of benzene resins of experiment 1 products are characterized, as for oils, by the decrease of their aromaticity degree with the increase of aliphaticity degree, while the resins of the benzene products from the experiment 2 and 3 demonstrate an opposite effect (Table 2). In the spectra of their benzene resins, the relative intensity of the absorption band $1600 \mathrm{~cm}-1$ increases with a significant decrease of the absorption band intensity in aliphatic structures of 1377 and 1459 $\mathrm{cm}-1$. The spectra of these products are also characterized by an aromatic triplet intensity increase in the range of $900-730 \mathrm{~cm}-1$, which indicates the occurrence of the processes with the development of condensed aromatic structures. The spectrum of benzene resins from experiment 3 , as well as in the oil spectrum of this experiment have the bands of about $1200-1100 \mathrm{~cm}-1$ corresponding to alcohols and ethers, which also confirms the course of oxidation processes under the given experimental conditions, which are reflected in the structural-group composition of heavy oil conversion products.

Alcohol-Benzene Resins. The spectra of alcoholbenzene resins of original oil and the products of experiments, as compared to the spectra of benzene resins, are characterized by a higher intensity of absorption bands for aromatic $\left(1600 \mathrm{~cm}^{-1}\right)$ and oxygen-containing $\left(1710 \mathrm{~cm}^{-1}\right)$ compounds (Fig. 3) As compared with the initial oil in the resins of experiment 1 products, the degree of aromaticity and oxidation increases and the degree of aliphaticity decreases. The alcohol-benzene resins of experiment 2 and 3 products undergo more pronounced changes, which is evident from the changes of their infrared spectra (Fig. 3). There is a significant increase in the intensities of the absorption bands characteristic of aromatic structures (1600 and 900-730 $\mathrm{cm}^{-1}$ ) with the intensity decrease of aliphatic structure absorption band (1377 and $\left.1459 \mathrm{~cm}^{-1}\right)$, which, along with the changes of their spectral indices (Table 2), indicates the increase in the degree of their aromaticity and the decrease of their aliphaticity degree. The spectra show a significant increase in the intensity of oxygen-containing structure absorption bands: at $1700 \mathrm{~cm}^{-1}$ (carbonyl groups), in the range of 1200$1100 \mathrm{~cm}^{-1}$ (alcohols and ethers), at $1030 \mathrm{~cm}^{-1}$ 
(sulfoxide groups). The band of $1286 \mathrm{~cm}-1$, which appears in the spectra of alcohol-benzene resins of the experiment 2 and 3, can be attributed to the valent vibrations of $\mathrm{C}-\mathrm{O}$ bonds in carbonyl groups [21].

These changes in the spectra are also reflected in the oxidation state increase of these products (Table 2 ). All changes in the structural-group composition of alcohol-benzene resins allow to confirm the course of oxidative catalytic cracking processes.

Asphaltenes and Coke Products. As was indicated above (Table 1), the asphaltenes of the test products obtained at the temperatures of $250,300{ }^{\circ} \mathrm{C}$, as compared to the asphaltenes of the initial oil and the experiment 1, consist of two fractions: soluble in an aromatic solvent (fr. A) and insoluble (fr. B), such as carbene-carboides, which differ from each other by their structural-group composition.

In the spectra of fraction $\mathrm{A}$ asphaltenes with the temperature increase up to $300{ }^{\circ} \mathrm{C}$, the intensity of the aromatic triplet increases in the range of 900$730 \mathrm{~cm}-1$ and the intensity of the absorption bands $1710,1200-1100,1030,500-400 \mathrm{~cm}-1$ is also increased (Fig. 4) which indicates the increase of oxygen group content in their structure.

In the spectrum of fraction $B$ asphaltenes of the experiment 3 (Figure 5b), as compared to the spectrum of fraction A asphaltenes of this experiment, a higher intensity of the absorption band $1600 \mathrm{~cm}^{-1}$ is observed, while the intensity of the aromatic triplet is reduced noticeably in the range of $900-730 \mathrm{~cm}^{-1}$. This allows us to conclude that under the conditions of these experiments the processes occur that are associated with the number of aromatic structures increase, and under the conditions of experiment 3 deeper structural transformations of the components take place toward their carbonization. The asphaltene spectrum of the fraction B, experiment 2 (Fig. 5a) differs from the spectrum of asphaltenes of the fraction A by higher intensity of absorption bands characteristic of aromatic structures (1600 and 900$\left.730 \mathrm{~cm}^{-1}\right)$. There are no absorption bands of carbonyl structures $\left(1710 \mathrm{~cm}^{-1}\right)$ in these spectra, the intensity of sulfoxide $\left(1030 \mathrm{~cm}^{-1}\right)$ and other oxygen-containing groups (1200-1100 $\left.\mathrm{cm}^{-1}\right)$ of absorption bands decreases. There is the decrease of the absorption band intensity at $1449,1376 \mathrm{~cm}^{-}$ 1 , which indicates the destruction of aliphatic structures of asphaltenes.

The spectra of the coke-like products (Fig. 5) obtained at 250 and $300{ }^{\circ} \mathrm{C}$ of the experiment 2 and 3 , similar to the spectra of insoluble asphaltenes, do not contain the absorption bands of the carbonyl groups and are characterized by a lower intensity of the absorption bands within sulfoxide, alcohol and ether groups. It can be assumed that the compaction and the condensation of aromatic groups takes place with the development of carbonized structures. Dealkylation processes also demonstrate a significant decrease of the absorption band intensity characteristic of aliphatic structures on the spectra of the coke-like products of this experiment.

The analysis of infrared spectra showed that a high degree of studied insoluble asphaltene and cokelike product aromaticity, as well as of the alcoholbenzene resins of the experiment 3 , does not agree with the values of their aromaticity $\left(\mathrm{C} 1=\mathrm{D}_{1600} /\right.$ $\left.\mathrm{D}_{720}\right)$ and aliphaticity $\left(\mathrm{C} 4=\left(\mathrm{D}_{720}+\mathrm{D}_{1380}\right) / \mathrm{D}_{1600}\right)$ spectral parameters (Table 2). This may be explained by a significant increase of aromatic triplet absorption band intensity in the range of 900$730 \mathrm{~cm}^{-1}$ within the spectra of insoluble asphaltenes and coke-like products, as in the case of benzene and alcohol benzene resins of the experiment 3 , thus the overlapping of the absorption band $720 \mathrm{~cm}^{-}$ ${ }^{1}$ takes place, the intensity of which is used in the calculation of the abovementioned spectral indices, which leads to low values of the aromaticity index at high values of paraffinity index. In order to analyze the content of long alkyl chains in the samples under study, according to the data of [28], a band of $685 \mathrm{~cm}^{-1}$ can be used, the intensity of which on the spectra of the experimental products under study is insignificant one. Consequently, insoluble asphaltenes have no long alkyl chains, thus they are not soluble in organic solvents.

It is known that coke is a complex disperse system in which crystalline formations of various sizes act as a disperse phase, and a dispersive medium is a gaseous or a liquid phase filling the pores from which adsorption-solvate layers are developed [28]. The analysis showed that its composition has a lower content of oils and a high content of resins and asphaltenes, both soluble and insoluble ones, in comparison with the liquid products of this experiment (Figure 6). The latter confirms the fact that coking takes place through the stage of insoluble asphaltene development, followed by their adsorption from a reaction system on the coke surface, which is deposited on the reactor wall surface.

The morphology of an initial coke-like product surface is represented in the form of an ordered porous structure (Figure 7a) with a pore size of about 2-5 $\mu \mathrm{m}$. The removal of a liquid phase leads to the transformation of a coke surface original structure, probably due to the destruction of its supramolecular structure, thus the coke surface acquires an amorphous character (Fig. 7b). The presence of white inclusions on microphotographs of a coke-like product before and after the extraction of the liquid phase can be conditioned by the presence of such inorganic compounds as metal salts and oxides, as well as hematite catalyst in these samples. 
The spectrum of the catalyst after the experiment 1 (Figure 8), as well as the coke spectrum, has the bands characteristic of organic compounds, in particular, $1600 \mathrm{~cm}-1$ band of aromatic structures, indicating the processes on its surface and the partial adsorption of the experiment products. The presence of a wide intense band at $3425 \mathrm{~cm}-1$ in the spectra, which was absent on the spectrum of an initial catalyst corresponding to the hydroxyl groups, confirms the development of iron complexes such as magnetite (III) - Fe3O4. The formation of magnetite is possible during hydrothermal-catalytic oil conversions, as the result of iron oxide interaction with water vapor [4].

\section{Conclusions}

Thus, the conducted studies of heavy oil conversion products by Fourier infrared spectroscopy have made it possible to establish their composition and structure and draw the following conclusions:

- At the temperature of $210^{\circ} \mathrm{C}$ and $1: 1$ ratio of water reaction system to oil, the chemical transformations of raw materials take place with the development of light hydrocarbons. The destruction of benzene and alcohol-benzene resins takes place according to the weakest bonds. It can be assumed that under these experimental conditions, the hematite and water catalyst act as hydrogen donors, preventing the development of unsaturated and oxidized structures.

- At the temperatures of 250 and $300{ }^{\circ} \mathrm{C}$ with a lower water content (the ratio of 1:5 and 1:10 for oil, respectively), more significant chemical transformations begin to occur, accompanied by the development of polymerization and condensation products in the form of insoluble asphaltenes and coke, characterized by a high degree of aromaticity. At the temperature of $250{ }^{\circ} \mathrm{C}$, the yield of hydrocarbons increases due to the destruction of long alkyl substituents of resins and asphaltenes with the development of aromatic compounds. At a low content of water in the reaction system, which was a hydrogen donor, these processes are also accompanied by oxidative processes and enhanced condensation, which leads to a significant yield of highly aromatic oxidized products.

The results of the experiments make it possible to offer the most favorable conditions for the process performance, corresponding to the experience 2 of this work, namely: $250{ }^{\circ} \mathrm{C}$ and the water-oil content of 1:5 at least to avoid oxidative processes.

\section{Summary}

In the course of the studies using Fourier infrared spectroscopy, the differences were set in the composition and the structure of heavy oil thermalcatalytic transformation products from Ashalchinsky deposit. The method of Fourier infrared spectroscopy makes it possible to fix the changes in the composition of products with a great accuracy and can serve as the control over the processes of heavy hydrocarbon raw material processing, also for the purpose of optimal conditions selection to carry out the processes.

\section{Acknowledgements}

The work is performed according to the Russian Government Program of Competitive Growth of Kazan Federal University.

\section{References}

1. J. Li, Y. Chen, H. Liu, P. Wang, F. Liu, "Influences on the aquathermolysis of heavy oil catalyzed by two different catalytic ions: $\mathrm{Cu} 2+$ and Fe3+", Energy and Fuels, vol. 27, №5, pp. 2555-2562, 2013.

2. A.K. Kurochkin, S.P. Toptygin, "Synthetic oil. Insufficient technology of heavy Russian oils processing on the fields", Sphere. Neftegaz, No. 1. - pp. 92-105, 2010.

3. R.R. Vezirov, I.R. Yavgildin, I.O. Tuktarova, et al., "Group chemical composition of fuel oil processing residue on an iron oxide catalyst", Chemistry and the technology of fuels and oils, No. 6, pp. 23-26, 1995.

4. V.I. Sharipov, N.G. Beregovtsova, S.V. Baryshnikov et al. "Pyrolysis of oil residue and some organic compounds in water vapor medium in the presence of hematite". Chemistry for sustainable development, No. 5, pp. 287-291, 1997.

5. B. Gu, J. Schmitt, Z. Chen, L. Liang, J.F. McCarthy, "Adsorption and Desorption of Natural Organic Matter on Iron Oxide: Mechanisms and Models", Environmental Science and Technology, vol. 28, №1, pp. 38-46, 1994.

6. N.N. Nassar, A. Hassan, P. Pereira-Almao "Comparative oxidation of adsorbed asphaltenes onto transition metal oxide nanoparticles", Colloids and surfaces A: Physicochemical and Engineering aspects, №384, pp.145-149, 2011.

7. R.R. Vazirov, S.P. Larionov, S.A. Obukhova et al. Oxidative catalytic conversion of heavy oil raw materials. Ufa: Reaktiv, 1999. - 132 p.

8. A.F. Kemalov, R. A. Kemalov, I. M. Abdrafikova, V.I. Gainullin, "Study of Natural Bitumen of Nagornoye Deposit, Troitskneft JSC (the Republic of Tatarstan, Russian Federation) aimed at Processing Options Determination", Asian Social Science, vol. 11, №3, pp. 296-304, 2014, doi:10.5539/ass.v11n3p296.

9. A.F. Kemalov, R.A. Kemalov, I.M. Abdrafikova, D.Z. Valiev, "Quantum energy calculations of technological parameters of electromagnetic impact on heavy hydrocarbons", Modern Applied Science, vol. 9, № 4, pp. 312-318, 2015

10. A.F. Kemalov, R.A. Kemalov, "Scientific and Applied Aspects of Regulating of High-Viscosity Oil", Indian Journal of Science and Technology, 
vol. 9, №8, 5 p, 2016, DOI: 10.17485/ijst/2016/v9i18/93734

11. I.M. Abdrafikova, G.P. Kayukova, S.M. Petrov, A.I. Ramazanova, R.Z. Musin, V.I. Morozov "Conversion of extra-heavy Ashal'chinskoe oil in hydrothermal catalytic system", Petroleum Chemistry, vol. 55, №2, pp. 104-111, 2015.

12. O.V. Kovaleva, "Transformations of natural bitumens during their thermolysis", Petrochemistry, Vol.44, No. 6, pp. 459-465, 2004.

13. Zh.A. Esetov, M.F. Turdiyev, A.F. Kemalov, I.M. Abdrafikova "Thermal-Steam Cyclic Processing Technology of Development Objects In Karazhanbas Kazakhstan Field", Indian Journal of Science and Technology, vol. 9, 8, 9 p, 2016, DOI: 10.17485/ijst/2016/v9i18/93749

14. B.A., Timerkaev, G.R., Ganieva, "Decomposition of heavy hydrocarbons in argon arc with the sunken electrodes", Journal of Physics: Conference Series, vol. 669, №1, 2016, article number 012061, DOI: 10.1088/1742-6596/669/1/012061

15. H. Yang, R. Yan, H. Chen, D.H. Lee, C. Zheng, "Characteristics of hemicellulose, cellulose and lignin pyrolysis”, Fuel, vol. 86, №12-13, pp. 17811788, 2007.

16. Barth, "Infrared spectroscopy of proteins (Review)", Biochimica et Biophysica Acta Bioenergetics, vol. 1767, №9, pp. 1073-1101, 2007

17. L.V. Ivanova, R.Z. Safieva, V.N. Koshelev, "Infrared spectrometry during the analysis of oil and petroleum products", Bulletin of the Bashkir University, Vol. 13, No. 4, pp. 869-875, 2008.

18. I.M. Abdrafikova, A.I. Ramazanova, G.P. Kayukova, I.I. Vandyukova, S.M. Petrov, G.V. Romanov. "Structural-group composition of heavy Ashalchinsk oil conversion products by the method of infrared Fourier spectroscopy". The bulletin of Kazan Technological University, No. 7, pp. 237 242, 2013.

19. N.K. Nayan, S. Kumar, R.K. Singh, "Production of the liquid fuel by thermal pyrolysis of neem seed", Fuel, vol. 103, pp. 437-443, 2013.

20. M. Bassbasi, A. Hafid, S. Platikanov, , R. Tauler, A. Oussama, "Study of motor oil adulteration by infrared spectroscopy and chemometrics methods", Fuel, vol. 104, pp. 798-804, 2013

21. B.N. Tarasevich. Infrared spectra of the main classes of organic compounds: reference materials. - Moscow: Publishing House of Moscow State University. Lomonosov Moscow State University, 2012. - $55 \mathrm{p}$.

22. L.M. Roev, S.V. Batychko, M.T. Russov. "The study of carbon monoxide adsorption on iron and nickel by infrared spectroscopy", Theoretical and experimental chemistry, Vol. 7, V. 2, pp. 232-237, 1971.

23. L.V. Serebrennikov, A.V. Golovkin. "Formaldehyde reaction with hydrogen peroxide. Infrared spectra in matrices from xenon and the calculation of intermediates and transition states",
The bulletin of Moscow University. Series 2. Chemistry, V. 46, No. 6, pp. 370-377, 2005.

24. T.A. Bulbak, T.N. Moroz, N.K. Nikandrova. "Natural and synthetic cordierites according to infrared and Mossbauer spectroscopy", Theory, History, Philosophy and the Practice of Mineralogy: Proceedings of IVth Intern. Mineralogical Workshop, Syktyvkar, May 17-20, 2006. Syktyvkar: Geoprint, 2006. - pp. 231-232.

25. Z.I. Syunyaev. The production, the refining and the application of petroleum coke. - M.: Chemistry, 1973. - $295 \mathrm{p}$.

26. V.P. Tverdokhlebov, S.A. Khramenko, F.A. Buryukin et al. "Petroleum coke for aluminum industry. Technology and properties", Journal of Siberian Federal University. Chemistry, No. 4, pp. 369-386, 2010.

27. S.I. Andersen, "Separation of asphaltenes by polarity using liquid-liquid extraction", Petroleum science and technology, №15, pp.185-198, 1997.

28. R. Perez-Hernandez, D. Mendoza-Anaya, G. Mondragon-Galicia et al., "Microstructural study of asphaltene precipitated with methylene chloride and n-hexane”, Fuel, № 82, pp. 977-9 